\section{Características generales de Aleph, la revista cultural más estable de Colombia}

\section{General characteristics of Aleph, the stable cultural magazine in Colombia}

DOI: http://dx.doi.org/10.18566/comunica.n40.a06

Recibido: 21/03/2019 - Aceptado: 29/05/2019

\section{Resumen}

La Revista Aleph nació en Manizales en 1966 y lleva 53 años de edición ininterrumpida por el empeño de su fundador Carlos Enrique Ruiz y de su esposa Livia González. La revista ha permitido la construcción de una red que incluye poetas, cuentistas, novelistas, ensayistas, pintores, escultores y músicos de América Latina y Europa. Aunque han circulado 188 números y su colección se encuentra completa en 13 bibliotecas colombianas y 13 extranjeras, es una revista poco estudiada, quizás porque encaja en lo que Ana Teresa Martínez (2013) denomina "intelectuales de provincia: entre lo local y lo periférico".

\section{Abstrac}

Aleph Magazine was born in Manizales in 1966 and has been uninterruptedly published for 53 years because of the joint efforts of his founder Carlos Enrique Ruiz and his wife Livia González. The magazine has allowed the construction of a network that includes poets, storytellers, novelists, essayists, painters, sculptors, and musicians from Latin America and Europe. Although 186 issues have circulated and its collection is complete in 13 Colombian and 13 foreign libraries, it is a poorly studied journal, maybe because it fits what Ana Teresa Martínez (2013) calls "province intellectuals: between the local and the peripheral".

\section{Presentación}

En la edición 27 del Boletín Bibliográfico del Banco de la República Rafael Gutiérrez Girardot (1991) referenció tres revistas culturales colombianas: Revista Gris, de Max Grillo; la Revista Contemporánea, de Baldomero Sanín
Comunicación

número 40

Enero-junio

2019 | pp. 75-89

\section{Adriana Villegas Botero}

Comunicadora social y periodista, y abogada.

Magíster en Estudios

Políticos de la Pontificia Universidad Javeriana. Directora de la Escuela de Comunicación Social y Periodismo de la Universidad de Manizales, Colombia. Miembro del Grupo de Investigaciones de la Comunicación de la Universidad de Manizales (categoría A en Colciencias). Identificador Orcid: 00000002-4978-3259
Palabras clave

Revistas culturales, Revista Aleph, Redes intelectuales, Redes periféricas.

Keywords

Cultural journals, Aleph

Magazine, Intellectual Networks, Peripheral Networks. 
Cano y La Gruta, de Federico Rivas Frade y Rafael Espinosa Guzmán. Las tres han sido ampliamente estudiadas en el ámbito académico y fueron incluidas por Jorge Orlando Melo (2008) en su lista cronológica sobre los principales suplementos y revistas culturales de Colombia. La lista de Melo incluye 138 títulos de revistas publicadas entre 1808 y 2007.

La Revista Gris circuló cuatro años, entre 1992 y 1995 la Revista Contemporánea se editó entre 1904 y 1905 y La Gruta se publicó entre 1903 y 1904. La corta vida de las tres es una característica común de la inmensa mayoría de las revistas incluidas en la lista de Melo. Como lo señaló Catalina González en una investigación sobre las revistas culturales en Colombia:

En los últimos 7 años se han fundado 39 de las 59 revistas culturales que circulan actualmente (el 68\% de ellas). Esto indica dos características: su poca perdurabilidad y su frecuente aparición. Se siguen fundando revistas culturales día a día pero su promedio de vida es corto, son efímeras. Aquellas revistas que sobreviven más tiempo son los suplementos y las revistas de empresas privadas (González, 1993).

Según el estudio del historiador Jorge Orlando Melo, la revista cultural independiente que de más larga vida en Colombia es la Revista Aleph, excluyendo los suplementos literarios de los periódicos y las revistas académicas universitarias. Su primer número circuló en octubre de 1966 y sigue editándose cada tres meses. Le siguen en longevidad las revistas Golpe de dados y Puesto de Combate, fundadas en 1973, que también continúan imprimiéndose.

Revista Gris, la Revista Contemporánea, La Gruta y otras como Eco, Mito, Lámpara y Crónica, lograron en su momento articular redes culturales, entendidas como las concibe Claudio Maíz (2011), es decir, que desde su lógica de enlace, "permiten, a través de sus entramados, la transferencia de tópicos culturales (ideas, modas, tendencias, etc.) prescindiendo de contactos personales o no siendo estos determinantes".

La Revista Aleph también articula una red cultural, pero a diferencia de las anteriores no existen hasta la fecha estudios académicos que den cuenta de su historia, características, contenidos, enfoque editorial o impacto. Quizás esta invisibilidad, a pesar de la magnitud y consistencia de su obra, obedezca a que tanto la revista como su director, Carlos Enrique Ruiz Restrepo, encajan en lo que Ana Teresa Martínez define como "intelectuales de provincia":

Los estudios de sociología de la cultura y de historia intelectual se han centrado particularmente en el análisis de campos culturales centrales y de productores culturales que han alcanzado consagración y reconocimiento 
al menos nacional. Este enfoque ha dejado fuera a intelectuales y espacios sociales considerados "locales" por su consideración periférica, que han incidido en la construcción de esos campos desde una posición marginal y que han desempeñado roles significativos en la reproducción, la circulación y la apropiación cultural (Martínez, A, 2013).

Lo que sigue a continuación es un intento preliminar de descripción de la Revista Aleph, desde sus orígenes hasta hoy, a partir de las voces de sus hacedores, teniendo en cuenta que la pareja Ruiz-González es escéptica sobre la posibilidad de que la revista pueda sobrevivir a la muerte de su fundador.

\section{Origen y generalidades de Aleph}

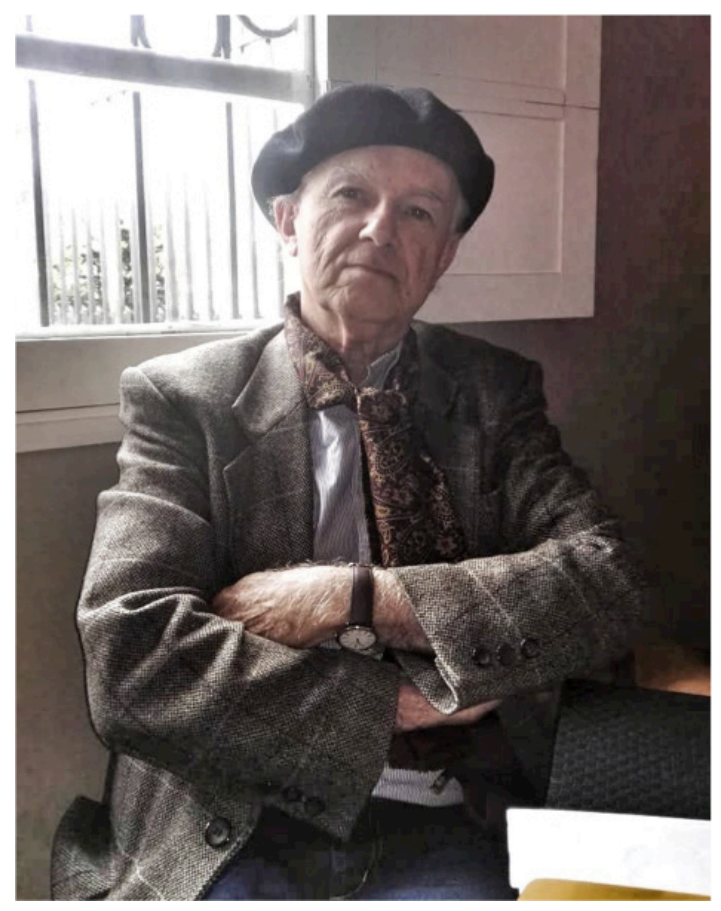

Carlos Enrique Ruiz

Foto: Adriana Villegas Botero

Lugar: Kafé Florida, Manizales

Fecha: jueves 5 de julio de 2018

Carlos Enrique Ruiz Restrepo fundó la Revista Aleph hace 53 años y desde entonces es su director. La revista ocupa buena parte de su tiempo y el de su esposa, la música Livia González Henao. Ambos tienen 76 años de vida y llevan 51 casados. Se conocieron en la universidad y han trabajado 
juntos desde el inicio de Aleph en el empeño por sacar adelante a la revista, así como la actividad cultural conexa a ella, que incluye conciertos, exposiciones, cátedras y edición de libros, entre otros proyectos.

Ruiz recuerda que la revista nació en Manizales en medio del agite intelectual que se vivía en la Universidad Nacional en los años 60. "En 1964 nosotros éramos más o menos 170 estudiantes de ingeniería y entramos en oposición con la Rectoría porque nos querían cerrar la carrera en nuestra sede y mandarnos a terminarla a Bogotá o Medellín. En junio de ese año asumió el nuevo rector, José Félix Patiño R., quien después de percatarse de la situación nos nombró un nuevo decano, Alfonso Carvajal Escobar, ingeniero de la Escuela de Minas y Arquitecto de París".

La crítica de arte Marta Traba dirigía en ese entonces la oficina de Extensión Cultural de la Universidad Nacional y también apoyó el surgimiento de Aleph.

En mi época del colegio con unos amigos sacábamos un periódico en mimeógrafo que se llamaba 'Gaceta' y otro que se llamó 'Atalaya' y luego en la universidad uno que denominamos 'Rumbos'. Por allá en 1966 algún día pensamos que podíamos hacer una revista para tener más eco que con los periodiquitos.

El primer número de la Revista Aleph circuló en octubre de 1966, con un breve ensayo sobre la última década del arte colombiano, escrito especialmente para la nueva publicación por Marta Traba. Al texto lo acompañaron otros ensayos que en conjunto, al estilo borgiano, mezclaban filosofía, ciencia y arte. La impresión se hizo en Editorial Renacimiento, adscrita al diario local La Patria, bajo el cuidado de la linotipista Pepita Parra. Esa primera edición circuló en el mismo formato que aún se conserva 53 años después: 17×24 cms, es decir un centímetro más pequeño que el de la conocida National Geographic. De esa edición, que costó mil pesos de la época, se imprimieron mil ejemplares. Unos cuantos se vendieron a peso y la mayoría se distribuyó gratuitamente entre bibliotecas, universidades y amigos del mundo cultural.

En 2016, con ocasión de los 50 años de Aleph, la periodista Gloria Luz Ángel, editora del suplemento cultural “Papel Salmón” del diario La Patria, entrevistó a Carlos Enrique Ruiz, quien le contó el origen del nombre de la publicación.

Tene doble connotación. Por entonces yo descubrí el cuento ‘El Aleph' de Borges en 'El retorno de los brujos' que leía, y me conquistó. Pero también, implícito en ese relato, estaba la referencia a la teoría matemática de los 'transfinitos', la 'Mengenlehre', desarrollada por el matemático alemán Georg Cantor (18451918), de la cual 'El Aleph' era el nombre del primer transfinito (primera letra del alfabeto hebreo). Y como estudiante de ingeniería tenía nada despreciable formación matemática, adopté el nombre, con apoyo de mis compañeros. 
Y con esa primera aparición (octubre 1966) quisimos hacer una revista que congregara aspectos de la ciencia, la técnica y el humanismo" (Ángel, 2016).

Aunque la mayoría de la gente al referirse al cuento de Borges dice Aleph, con el acento en la última sílaba, Ruiz pronuncia el nombre de su revista como si la palabra llevara tilde en la a inicial: "Aleph es la primera letra del alfabeto hebreo. Es una palabra hebrea y su pronunciación correcta es la que le da el nombre a la revista".

En 1967 Ruiz se graduó como ingeniero civil de la Universidad Nacional sede Manizales, estudios que combinó con su asistencia a distintas clases en la Facultad de Filosofía y Letras de la Universidad de Caldas. El nuevo ingeniero empezó a trabajar en su profesión y luego partió a Popayán para especializarse en vías terrestres. En 1971 regresó a la Universidad Nacional en calidad de docente y en septiembre de ese mismo año circuló la segunda edición de Aleph, casi cinco años después de la primera. Seis meses después salió la tercera edición, que ya incluyó ensayos de firmas internacionales y a partir de allí la revista empezó a salir con regularidad, primero cada cuatro meses y luego cada tres, que es como se mantiene hoy.

El gran cambio que le permitió configurar la línea editorial que aún conserva, ocurrió después de la edición 5, de junio de 1973. Los primeros números fueron apoyados económicamente por la Universidad Nacional hasta que el antropólogo Luis Duque Gómez asumió la rectoría de la institución y suspendió el apoyo por considerar que la revista era de izquierda. Ruiz comenta que nunca supo si tal calificativo se debió a algún contenido publicado o a las firmas que participaban en la revista y atribuye la censura al ambiente político de la época. Para ese entonces las FARC tenían 9 años desde su creación, la protesta social y universitaria era fuerte y se miraba con recelo a la intelectualidad, en un contexto político en el que estaba próximo a llegar a su fin el Frente Nacional, que previó la alternación de la Presidencia de Colombia entre el Partido Liberal y el Partido Conservador, sin opción de acceso al poder a otros grupos políticos por un período de 16 años.

Carlos Enrique Ruíz negoció con la Universidad la posibilidad de seguir editando Aleph bajo su cuenta y riesgo y así lo viene haciendo desde la edición 6, correspondiente al trimestre enero/abril de 1974. Desde entonces la revista se parece mucho a los intereses de su director, quien ha vivido en el mundo académico y ha publicado varios libros de poesía: los contenidos ofrecen variedad de géneros y temas, aunque los aspectos de ingeniería que aparecieron en las primeras ediciones dejaron de tener espacio en Aleph para trasladarse a otra revista fundada por Ruiz: el Boletín de Vías dedicado a temas técnicos como vías, transporte y geotecnia, que nació en 1972 y tuvo 100 ediciones, hasta su último número en 2006. 
La orfandad económica en que quedó Aleph tras la falta de apoyo de la Universidad Nacional en 1973 se sustituyó con la Fundación Aleph, esfuerzo en el que participaron varios amigos de la familia Ruiz-González y que le dio cierta tranquilidad económica a la revista, al punto que el tiraje subió a 2000 ejemplares por edición, lo cual es significativo si se tiene en cuenta que desde sus inicios hasta hoy los costos más altos de la revista corresponden no a la producción de la misma sino a la distribución, porque su director ha querido que llegue a distintos países de América y Europa. De hecho en sus primeros 20 años la Revista Aleph se distribuyó entre más de 300 bibliotecas nacionales e internacionales, pero la falta de presupuesto obligó a reducir los envíos.

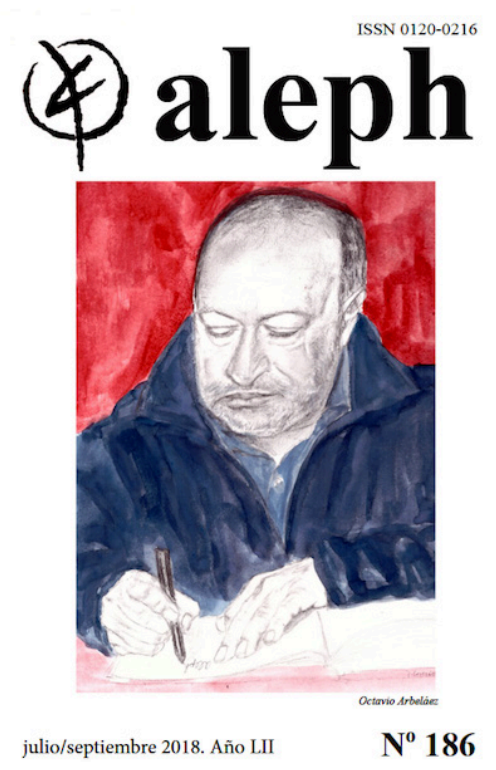

Carátula 186 Fuente: tomada de http://www.revistaaleph.com.co /

Ruiz alternó el ejercicio ad honorem de la dirección de Aleph con otros cargos que le permitieron cultivar la red de relaciones que se refleja en la revista: fue director de la Biblioteca Nacional de Colombia en Bogotá (1984-1985), Viceministro de Educación Nacional (1995-1996) y Ministro encargado en varias ocasiones en el mismo período. También fue Rector de la Universidad de Caldas, entre 2001-2003 y desde 1996 es Miembro de la Academia Colombiana de la Lengua, correspondiente de la Real Academia Española de la Lengua.

En los años 80 la Fundación Aleph cesó su trabajo y fue entonces cuando apareció como salvavidas el apoyo de la Fundación Mazda, con el mecenazgo del también ingeniero manizaleño José Fernando Isaza Delgado, quien 
continuó liderando el apoyo económico a Aleph hasta 2006 cuando se retiró para ocupar la rectoría de la Universidad Jorge Tadeo Lozano. Desde entonces el soporte financiero de la revista ha recaído de manera exclusiva en la pareja Ruiz-González, que asume los costos de edición y distribución de la revista a partir de sus mesadas como jubilados de la docencia universitaria.

La revista se imprimió inicialmente en la Editorial Renacimiento de La Patria; luego, por muchos años en la Veyco, empresa de don León Villegas e hijos; después en la Editorial Andina, empresa de Jorge Escobar, y en años más recientes en Arte Nuevo, de Jerónimo y Gregorio Matijasevic.

En la actualidad el tiraje oscila entre 60 y 600 números, aunque el promedio son 200 ejemplares por cada edición, de los cuales una parte se envía gratuitamente a bibliotecas y universidades de Colombia y el exterior. Sin embargo en los últimos tiempos la circulación se ha concentrado en la página web www.revistaaleph.com.co en donde se pueden consultar las ediciones completas desde el número 126/127, correspondiente al período julio-diciembre de 2003, hasta hoy. La versión digital incluye todos los textos, manuscritos, partituras, ilustraciones, pinturas y demás elementos que conforman cada una de las ediciones. El promedio de consultas en la web es de 3.600 visitantes únicos por mes.

En su formato la revista ha tenido pocos cambios desde su fundación. Lo único variable es el número de páginas, que depende del material disponible: a veces son 80 páginas y a veces 200. La carátula suele ser una pintura o ilustración original, donada por algún artista de manera exclusiva para la edición. El interior va todo en blanco y negro, con escasas imágenes y páginas diagramadas a una o dos columnas, aunque se pueden ver ilustraciones, gráficos, tablas, partituras y de vez en cuando fotografías. La primera sección siempre es un manuscrito de algún artista, escritor, músico o ensayista, que puede ocupar una o varias páginas, y luego vienen los ensayos que se intercalan con poemas, reseñas, entrevistas, cuentos y partituras.

Aunque Ruiz recibe colaboraciones de conocidos y desconocidos que le envían material para publicar, buena parte del contenido tiene origen en solicitudes expresas que el director hace a los autores. Así, su labor consiste en pedir el material, recibirlo, editarlo, hacer el prediseño de la revista, encargarse de las labores relacionadas con la publicación de los contenidos y actualización de los índices en la página web, y empacar y distribuir los ejemplares que se envían como cortesía a distintos países. Su esposa Livia presta un apoyo fundamental en cada una de estas actividades, aunque no participa en la edición online de la revista. 
Nombres, temas y contenidos

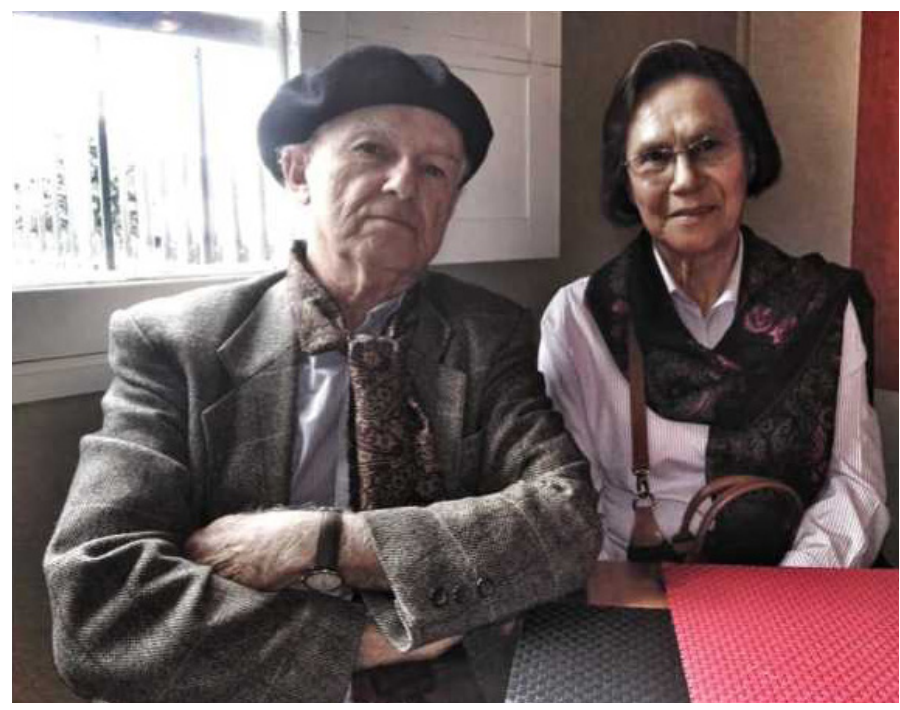

Carlos Enrique y Livia Foto: Adriana Villegas Botero Lugar: Kafé Florida, Manizales Fecha: jueves 5 de julio de 2018

"Las relaciones que cultiva Carlos-Enrique Ruiz con su revista Aleph, de Manizales, le sirven a Colombia más en la sociedad literaria de nuestra América y España que ninguna revista de Bogotá", declaró en 1996 el intelectual colombiano Germán Arciniegas.

Esa valoración sobre la trascendencia de la revista, que coincide con opiniones expresadas por otros como el ex presidente Alfonso López Michelsen o el escritor Eduardo Escobar, contrasta con la propia visión del director, quien en 1988, en la conferencia Aleph: crónica de una obsesión, dijo las siguientes palabras, que aún suscribe:

No quiero hacer ver la experiencia de Aleph como algo singular y de cierta trascendencia. Por el contrario, hoy la veo como un hecho rutinario de mi vida, con las emociones propias, personales, solitarias si se quiere, sin incidencia alguna frente al medio y mucho menos en el acontecer general de la cultura. Por el solo hecho de haber sido recibida, una y otra vez, por ciertas manos solidarias y entusiastas en lugares bien disímiles de la geografía, la revista Aleph tiene su justificación central. Y además, porque la hago para personas cercanas (Ruiz, 1998). 
En un país centralista como Colombia, resulta exótico que una revista cultural editada en Manizales, una ciudad que hoy tiene escasos 400.000 habitantes, logre no solo una larga permanencia en el tiempo sino también tejer desde la provincia la red de contactos internacionales que ha propiciado Aleph, en un ejercicio constante por mostrar los procesos creativos que pasan por Manizales, Caldas y el Eje Cafetero, así como traer a la región las obras, autores y discusiones que se dan en otras geografías, sin la presión del mercado ni las luminarias mediáticas, en un flujo de múltiples vías. El logro se explica en parte por ser Manizales una ciudad universitaria con un número importante de académicos que han escrito en Aleph, así como de profesores internacionales que por sus contactos con la ciudad conocen la revista, pero también por la curaduría que hace su director y por la disciplina en las labores de edición.

"La Revista Aleph es un fósil. Es de las más antiguas de América Latina. Mi apuesta ha sido por mantener una oferta que no guarda relación con el mercado y que, al contrario privilegia la calidad de las obras y autores que no responden a la moda", dice Ruiz. Ese criterio editorial explica en parte su larga permanencia en el tiempo, que también obedece a la disciplina por garantizar una periodicidad constante: "La revista es trimestral y sale porque sale. Siempre circula a tiempo", agrega su esposa Livia.

Poco antes de su muerte en 2016 el periodista Jorge Consuegra transcribió un largo diálogo sostenido con Ruiz en el que destaca algunos de los contenidos más significativos de Aleph en sus primeros 50 años:

La revista ha presentado un buen número de ediciones monográficas, como las dedicadas a la cultura en España, Israel, México y Argentina; igualmente, sobre personalidades como Miguel de Unamuno, Alfonso Reyes, Fernando Pessoa, Michel de Montaigne, Fernando Charry Lara, Rafael Gutiérrez Girardot, Jorge Luis Borges y Gabriel García Márquez; o con respecto a obras como El Quijote; y sobre temáticas como "Los intelectuales y el poder", "La educación por el arte", “La Justicia”... Spinoza, Danilo Cruz-Vélez, Jean-Jacques Rousseau, Eduardo Caballero-Calderón, Jorge Zalamea, Armando Romero, Eduardo GarcíaAguilar, La literatura del pueblo chicano, María Zambrano... Recordadas un poco a saltos (Consuegra, 2016).

Otro capítulo de la historia de la revista son los "Reportajes de Aleph", que en realidad consisten en entrevistas a artistas, científicos, escritores o humanistas. Entre los más de 80 diálogos que han sido reproducidos en Aleph dentro de esta serie están las conversaciones con Juan Rulfo, Germán Arciniegas, Ben-Ami Scharfstein, Oswaldo Guayasamín, José Luis Cuevas, Jacques Gilard, Dámaso Alonso, Gonzalo Drago, Luis Cardoza y Aragón, Marcela del Río-Reyes, Fernando Salmerón, Octavio Paz, Matilde 
Espinosa, Alí Chumacero, Rafael Gutiérrez-Girardot, , José-María Valverde, Fernando Savater, Atahualpa del Cioppo, Gordon Brotherston, Nirma Zárate, Günther Haensch, Mario Benedetti, Ernesto Guhl, José Prat, Blas Galindo, Germán Pardo García, Francisco Miró Quesada, Emma Reyes, Georges Lomné, Leopoldo Zea, Juan Friede, José Félix Patiño, Jorge Arias de Greiff, Jaime Jaramillo-Uribe, Paul Holdengräber, Léopold Sédar-Senghor, Rafael Humberto Moreno-Durán, Juan Herkrath, Isabel Aretz y L.F. Ramón y Rivera, Georges Lomné y José Antonio Jiménez-Salas, entre muchos otros.

Una selección de estos "Reportajes de Aleph" fue publicada en dos volúmenes por la Editorial de la Universidad de Caldas, en los años 2007 y 2016. El primer tomo tiene 546 páginas y el segundo 720.

Otra característica de la Revista Aleph ha sido la publicación de obras de artistas plásticos en todas sus carátulas, así como en páginas interiores. El maestro Alejandro Obregón donó tres carátulas y su nombre se suma al de otros pintores que han pasado por la revista con contribuciones específicas como Oswaldo Guayasamín, Rogelio Salmona, José Luis Cuevas, Enrique Grau, Emma Reyes, David Manzur, Alipio Jaramillo, Juan Calzadilla, Colombo Gazzoni, Pedro-Nel Gómez, Luciano Jaramillo, Guillermo Botero G., LuzMaría Ángel, Carlos-Augusto Buriticá, Gonzalo Ariza, Rodrigo Granada, Cosme Jaramillo, Luis-Alfonso Orozco, Luz-María Jaramillo, Guillermo Páramo, Adolfo Peña, Jorge Elías Triana, Mario Rivero, Sergio Trujillo Magnenat, María Victoria Vélez, y el caso especial de Pilar González-Gómez, nieta del maestro Ricardo Gómez Campuzano y quien se convirtió en ilustradora habitual de la Revista.

A los monográficos, los reportajes y las ilustraciones se suman dos particularidades de Aleph: los manuscritos autógrafos que abren cada edición, en especial de poetas, aunque los hay también de músicos, cuentistas, novelistas y ensayistas, entre los que figuran textos de puño y letra de Juan Rulfo, García Márquez, Álvaro Mutis, Isaiah Berlin, Victoria Camps, Enrique Buenaventura y Joan Manuel Serrat, entre muchos otros. La segunda novedad son las partituras en las que se nota la impronta de Livia González Henao. El índice de la revista disponible en su página web da cuenta de 43 partituras de 22 compositores, que incluyen pasillos, bambucos, bundes y otros ritmos colombianos, así como sinfonías, suites para orquesta y composiciones para piano, violín y clarinete. Sobre esa variedad de contenidos dijo Ruiz en una entrevista en 2006:

Sería de mi parte exagerado decir que Aleph es un medio testimonialy transmisor del pensamiento iberoamericano, aunque en sus páginas han escrito autores del mundo hispánico, y no solo de este. Nuestra labor es modesta, y siempre queda la incertidumbre sobre su utilidad real. No dejamos de intercambiar comunicaciones y puntos de vista con lectores esparcidos por el mundo, con 
personalidades intelectuales que nos han honrado con su amistad, además de lectores avisados. En las páginas de Aleph ha habido un trabajo que reúne creadoresy pensadores sobre diversos asuntos, sin encasillamientos ideológicos, políticos, religiosos o filosóficos. Somos de la convicción de permanecer en una incesante búsqueda, con perseverante diálogo, por la verdad y la belleza, en convergencia de poesía, ensayo literario y filosófico, cuento, con expresiones de la plástica (caso singular de las carátulas e ilustraciones interiores), y lo hubo por tiempos, en forma de separatas centrales, de la música (...) En sus páginas, reitero, hay análisis de continuo debate, en expresión de autores de todas partes, en los diversos géneros, incluyendo los de creación, en especie de coexistencia armónica de poesía y humanismo (Ángel, 2006).

\section{De provincia, con enfoque global}

Desde el origen de Aleph, Ruiz tuvo claro que el esfuerzo se justificaba si la revista podía trascender el entorno montañoso en donde se producía y por eso buena parte del presupuesto se ha destinado a su distribución, que en una época fue paga y desde hace muchos años es gratuita.

Gracias a ese esfuerzo hoy hay colecciones completas de Aleph en al menos 13 bibliotecas colombianas, así como en otros ocho países. En Colombia se puede consultar en las tres bibliotecas de la Universidad Nacional de Colombia sede Manizales, Universidad de Caldas, Banco de la República sede Manizales, Hemeroteca Nacional de la Universidad Nacional en Bogotá, Biblioteca Nacional de Colombia, Biblioteca Luis Ángel Arango, Instituto Caro y Cuervo, Casa de Poesía Silva y Biblioteca de la Universidad Javeriana, a la que le faltan unos pocos ejemplares. Así mismo en Medellín está disponible en la Biblioteca Pública Piloto y la hemeroteca de la biblioteca central de la Universidad de Antioquia.

Aleph también está disponible en seis bibliotecas de Estados Unidos: Biblioteca del Congreso y las de las universidades de Texas, Illinois, Stanford, California y Pittsburg. En Alemania la colección completa está disponible en el Instituto Iberoamericano de Cultura de Berlín; en el Reino Unido en la Biblioteca Británica de Londres; en España en la Biblioteca Hispánica de la Agencia Española de Cooperación Internacional de Madrid; en Argentina en la Biblioteca Nacional de Buenos Aires; en Cuba en la Casa de las Américas de La Habana; en Costa Rica en el Sistema de Bibliotecas de la Universidad de Costa Rica en San José, y en Israel en la Biblioteca Nacional de Israel con sede en Jerusalén.

Según Ruiz, tener en las páginas de Aleph firmas de distintas disciplinas y geografías ha sido posible gracias a una red de colaboradores, que funciona 
por amistades que a veces nacen a partir de una carta o un correo electrónico de alguien que se acerca a la revista, y que luego de mucho diálogo epistolar o digital han logrado concretarse con un encuentro físico en Manizales o en cualquier otro lugar de América o Europa. Entre esos colaboradores frecuentes Ruiz destaca a la poeta y académica Graciela Maturo en Argentina, a la ilustradora y pintora Pilar González Gómez en España, a la pareja conformada por María Esther Aguirre Lora y Ramón Mier en México, al poeta Alfredo Chacón en Venezuela, al ensayista y poeta Pedro Lastra, en Chile, a la traductora uruguaya María Elena Szilágyi Chebi, en Hungría, y al profesor de literatura de la Universidad de Connecticut Antonio García Lozada, en Estados Unidos, entre muchos otros. Sobre esa red dijo Ruiz en 2006:

En general las revistas culturales tienen limitaciones muy fuertes para su circulación, puesto que no hacen parte de ese engranaje complejo y endemoniado de los intereses comerciales, mercantilistas. Hablo, en especial, por Aleph, que ha ido tejiendo una red nacional e internacional de amistades, como receptores, que a la vez generan espacios de diálogo permitiendo que la revista tenga una dinámica propia (Ángel, 2006).

\section{Cátedras y libros Aleph}

La labor musical de Livia González Henao y las colecciones acumuladas de originales de pinturas e ilustraciones donadas por distintos artistas plásticos para la revista fueron el germen que le permitió a la pareja RuizGonzález empezar a programar conciertos y exposiciones esporádicas en torno a la actividad de Aleph.

Sin embargo, el proyecto de expansión más significativo es la Cátedra Aleph, que nació en 2002 y se ofrece como una asignatura electiva de contexto de la Universidad Nacional. Se trata de un curso orientado por Carlos Enrique Ruiz para 25 estudiantes de distintos programas, no solo de la Universidad Nacional sino también de otros centros de educación superior de Manizales, que cada semestre versa sobre un tema distinto, bien sea la obra de un artista o algún tema filosófico de reflexión. El Quijote, Albert Einstein, Harold Bloom, Karl Popper, Cien años de soledad, Albert Camus, el fanatismo, la paz y la intelectualidad han sido algunos de los temas tratados. La versión 32 de la Cátedra, correspondiente al segundo semestre de 2018, versó sobre la poesía y el pensamiento de la argentina Graciela Maturo.

Este espacio se suma a la Cátedra Abierta Grandes Temas de Nuestro Tiempo, que coordinó Ruiz en la Universidad Nacional entre 1990 y 2015, aunque hoy hay planes de reabrirla. En ella estudiantes de secundaria y universidad, así como la ciudadanía en general, pueden participar en conferencias que 
ofrecen distintos invitados nacionales e internacionales. El bicentenario de la Independencia y De los Presocráticos a Pessoa fueron dos de las cátedras realizadas, cuyas memorias fueron publicadas en formato de libro por la Universidad Nacional.

Otro frente de expansión de la publicación es el sello editorial "Ediciones Revista Aleph", bajo el cual Ruiz ha editado no solo distintos volúmenes de poesía de su autoría, sino también ensayos como Meditación acerca del Desasosiego de Pessoa, El clamor de la clepsidra, Matilde Espinosa en la contienda de vida y poesía, Los signos de la espera y Cien años de soledad en el espejismo de la nostalgia, entre otros.

"Las cátedras, los libros y la revista obedecen a un interés personal que tengo de romper con el espíritu pragmático y utilitarista de la universidad de hoy, que vive enfrascada en los temas de indexación y puntos y se olvidó de convocar a las personas de la calle y de discutir los grandes temas humanísticos", explica Ruiz.

Aunque en los últimos tiempos la revista ha reducido su tiraje, Ruiz está seguro de que seguirá circulando mientras él viva. Sin embargo, se muestra inseguro frente a la supervivencia de la publicación tras su ausencia. "Desde que cumplí 70 años empecé a ser consciente de la inminencia de la muerte. Ojalá alguna entidad, una universidad o biblioteca, garantizara la continuidad de la revista y la conservación del archivo, que debe permanecer junto, no dividido". La aclaración obedece a que le han ofrecido que si hace un inventario de los manuscritos, partituras y obras pictóricas originales que tiene le pueden comprar algunas, pero su interés es que todo el archivo de Aleph se conserve en un solo lugar.

Aleph no tiene sede propia ni personería jurídica. Funciona en la casa de la pareja Ruíz-González en el barrio Alta Suiza, de Manizales, y el enorme archivo físico de 53 años de revista se encuentra bien organizado y clasificado, aunque de forma empírica. El archivo incluye carpetas y cajas de plástico y madera con textos, fotografías en papel, recortes de prensa, partituras, manuscritos, diapositivas, grabaciones en cintas, casetes y microcasetes, originales de pinturas, ilustraciones y dibujos, grabados en madera y metal, cartas y postales, afiches, así como la biblioteca personal de su director, en donde hay espacio especial para la obra de Gabriel García Márquez, Cervantes, Pessoa y Montaigne.

Al preguntarles por el futuro, tanto Livia como Carlos Enrique se enfocan en el archivo, más que en la revista. La pareja parece resignada a que Aleph no les sobreviva ya que se trata de un esfuerzo descomunal que implica tiempo y sacrificios económicos que quizás ninguna otra persona natural 
tenga la capacidad de asumir. De hecho, ninguno de sus tres hijos les ha manifestado interés en relevarlos en su labor, y sus cinco nietos aún son pequeños. Por lo pronto, mientras lo inminente ocurre, los Ruiz-González siguen editando su revista trimestral con la puntualidad de un relojero, y actualizan permanentemente los índices de autores, ilustradores, partituras y contenidos, pues saben que en 53 años de publicación y 188 números hasta septiembre de 2018 hay material suficiente para que varias generaciones se dediquen a investigar huellas de la cultura, el arte y el humanismo desde 1966, en América Latina y Europa.

\section{Referencias}

\section{Publicaciones periódicas}

Ángel, G. (2006). Entrevista de Gloria Luz Ángel con Carlos-Enrique Ruiz para "Papel Salmón". La Patria. Disponible en: http://www.revistaaleph.com.co/historia/29-entrevista-acarlos-enrique-ruiz-para-qpapel-salmonq-2006.html (Recuperado el 6 de julio de 2018).

Ángel, G. (2016). Entrevista de Gloria Luz Ángel con Carlos-Enrique Ruiz para "Papel Salmón". La Patria. Disponible en http://www.revistaaleph.com.co/historia/533-entrevista-degloria-luz-angel-con-carlos-enrique-ruiz-para-papel-salmon-2016.html (Recuperado el 7 de julio de 2018).

Arciniegas, G. (1996). Aleph. El Tiempo. Disponible en http://www.eltiempo.com/archivo/ documento/MAM-581194 (Recuperado el 7 de julio de 2018).

Consuegra, J. (2016). Entrevista de Jorge Consuegra con Carlos-Enrique Ruiz, a propósito de los ¡50 años! de la Revista Aleph. Disponible en http://www.revistaaleph.com. co/historia/532-entrevista-con-carlos-enrique-ruiz-de-jorge-consuegra-2016.html (Recuperado el 6 de julio de 2018).

González, C. (1993). La revista cultural colombiana: tendencias. Revista Signo y pensamiento. (Pontificia Universidad Javeriana), (23), 87-96. Disponible en http:// www.javeriana.edu. co/signoyp/pdf/2306.pdf

Gutiérrez Girardot, R. (1991). Tres revistas colombianas de fin de siglo. Boletín cultural y bibliográfico (Banco de la República, Biblioteca Luis Ángel Arango), 28(27), 3-18. Disponible en https://publicaciones.banrepcultural.org/index.php/boletin_cultural/ article/view/2342

Maíz, C. (2011). La eficacia de las redes en la transferencia de bienes simbólicos: el ejemplo del modernismo hispanoamericano. Revista Alpha (Universidad de los Lagos), (33), 23-41. Disponible en https://scielo.conicyt.cl/scielo.php?script=sci_ arttext\&pid=S0718-22012011000200003

Manrique Ochoa, M. A. (2009). Las revistas culturales y la difusión de las ideas políticas modernas en Colombia. Comunicación y ciudadanía. (Universidad Externado de Colombia), (1), 98-105. Disponible en https:// revistas.uexternado.edu.co/index.php/ comciu/article/view/1833/1639 
Martínez, A. T. (2013). Intelectuales de provincia: entre lo local y lo periférico. Prismas, Revista de historia intelectual. (Universidad de Quilmes), (17), 169-180. Disponible en http:/ / www.scielo.org.ar/scielo.php?script=sci_arttext\&pid=S1852-04992013000200005

Melo, J. (2008). Las revistas literarias en Colombia e Hispanoamérica: una aproximación a su historia. Colombia es un tema. Textos sobre literatura. Disponible en http://www. jorgeorlandomelo.com/bajar/revistas_suplementos_literarios.pdf

Ramírez, F. (2007). "Honoris causa a un socrático". La Patria. p. 13-A . Disponible en: http://www.revistaaleph.com.co/historia/26-qhonoris-causa-a-un-socraticoq.html (Recuperado el 6 de julio de 2018).

Ruiz, C. (1979). La revista ALEPH como una realidad cultural de la provincia colombiana. Revista Aleph (Ediciones Aleph), (30), 3-7.

Ruiz, C. (1998). Aleph: crónica de una obsesión. Revista Aleph (Ediciones Aleph), (66), 3-15.

\section{Vídeos}

Ruiz, C. (2014, mayo). Archivos de la Revista Aleph en la crónica de una obsesión. Muestra de su acervo cultural en 48 años de existencia. Vídeo disponible en https: / / www.youtube. com/watch?v=w6cpAdQeSy8 (Recuperado el 8 de julio de 2018). 